\title{
ANALISIS MANAJEMEN PENGELOLAAN SISTEM REKAM MEDIS PADA PUSKESMAS PAAL X KOTA JAMBI
}

\section{Analysis Of Management Management Of Medical Record Systems In Puskesmas Pal X Jambi City}

Hubaybah $^{1}$

${ }^{1}$ Program Studi Kesehatan Masyarakat, FKM Universitas Jambi

\begin{abstract}
Abstrak
Rekam medis merupakan salah satu dasar penilaian mutu pelayanan medik dari sebuah rumah sakit atau puskesmas. Petugas rekam medis mempunyai tugas dan tanggung jawab yang besar dalam menjaga keutuhan sebuah rekam medis. Petugas rekam medis diharapkan benar-benar mengetahui seluk beluk dari rekam medis secara luas dan mendalam. Tujuan penelitian ini adalah untuk mengetahui manajemen pengelolaan sistem rekam medis di Puskesmas Pal X Kota Jambi dalam rangka peningkatan mutu pelayanan Puskesmas kedepan. Penelitian ini dilakukan dengan metode penelitian kualitatif dengan wawancara mendalam kepada informan. Subyek pada penelitian ini adalah petugas rekam medis, kepala puskesmas, dokter dan perawat. Hasil penelitian menunjukkan bahwa petugas rekam medis yang ada di Puskesmas Pal X masih belum memenuhi standar, baik dari segi kualitas maupun kuantitas, tetapi dari segi pemahaman, petugas rekam medis di Puskesmas Pal X sudah memiliki pemahaman tentang rekam medis dengan cukup baik. Sarana dan prasarana yang ada di bagian rekam medis juga belum lengkap dan terbatas. Dalam pelaksanaan kegiatan, sudah dilakukan sesuai SOP yang ada, sehingga kerjasama antara petugas loket pembayaran dan upaya kesehatan perorangan juga dirasa sudah baik, begitu pula dengan alur rekam medis, sudah berjalan sesuai dengan SOP.
\end{abstract}

Kata Kunci: Analisis, Pengelolaan, Sistem, Rekam Medis

\begin{abstract}
Medical record is one of the basic medical service quality assessment of a hospital or clinic. The records officer has the task and a great responsibility in maintaining the integrity of a medical record. The records officer is expected to really know the ins and outs of medical records is broad and deep. The purpose of this study was to determine how the management of medical records system at the community health center X Pal Jambi City in order to improve the quality of health center services in the future. This research was conducted by the method of qualitative research with in-depth interview to the informant. Subjects in this study were medical records clerk, head of the clinic, doctors and nurses. The results showed that the medical records officer in community health center Pal X still does not meet the standard, both in terms of quality and quantity, but in terms of understanding, medical records clerk at the community health center X Pal own understanding of the medical record pretty well. Facilities and infrastructure that exist at the medical records of PHC Pal $\mathrm{X}$ is also incomplete and limited. In the implementation of activities already carried out in accordance SOP, so that cooperation between officers checkouts and individual health efforts also it is considered good, as well as the flow of medical records, has been running in accordance with the SOP.
\end{abstract}

Keywords: Analysis, Management, Systems, Medical Record

Korespondensi: Hubaybah

Email: beebeeideh@gmail.com 


\section{PENDAHULUAN}

Salah satu bentuk pelayanan kesehatan untuk menunjang tercapainya derajat kesehatan adalah Pusat Kesehatan Masyarakat (Puskesmas). Pusat Kesehatan Masyarakat (Puskesmas) adalah unit pelaksanaan teknis dinas kesehatan kabupaten/ kota yang bertanggungjawab menyelenggarakan pembangunan kesehatan disuatu wilayah kerja ${ }^{1}$. Faktor penting penunjang pelayanan puskesmas adalah rekam medis.

Rekam medis adalah keterangan baik yang tertulis maupun terekam tentang identitas, anamnesis, pemeriksaan fisik, laboratorium, diagnosa serta segala pelayanan dan tindakan medis yang diberikan kepada pasien, dan pengobatan baik yang dirawat inap, rawat jalan maupun yang mendapatkan pelayanan gawat darurat ${ }^{2}$.

Pengelolaan rekam medis di puskemas terdiri dari cara pemberian nomor rekam kesehatan keluarga, assembling, analisa kelengkapan, penyimpanan dan distribusi. Cara pemberian nomor rekam kesehatan keluarga (RKK) di Puskesmas menggunakan kode yang berbeda untuk didalam wilayah kerja maupun diluar wilayah kerja puskesmas dan kemudian ditambahkan 2 digit nomor ekstra didepan sebagai kode kepala keluarga, istri maupun anak dan selanjutnya dimasukan kedalam satu map folder ${ }^{3}$.

Untuk kegiatan assembling petugas menyusun lembaran formulir sesuai dengan nomor urut rekam kesehatan keluarga (RKK) dan mengganti map berkas rekam kesehatan keluarga (RKK) apabila map sudah rusak. Untuk kegiatan analisa kelengkapan petugas melengkapi formulir apabila pencatatannya tidak lengkap. Untuk kegiatan penyimpanan, petugas menyimpan formulir ke dalam map berkas rekam kesehatan keluarga (RKK) sesuai dengan nomor dan menyimpan kedalam lemari penyimpanan. Untuk kegiatan pendistribusian petugas mendistribusikan berkas rekam kesehatan keluarga (RKK) ke poliklinik yang dituju oleh pasien. Pendistribusian berkas rekam kesehatan keluarga (RKK) langsung dilakukan oleh petugas yang berwenang ${ }^{2}$.

Di dalam Peraturan Menteri Kesehatan (Permenkes) Nomor 749a tahun 1989 disebutkan bahwa setiap sarana pelayanan kesehatan wajib menyelenggarakan Rekam Medis. Rekam Medis adalah berkas yang berisikan catatan dan dokumen tentang identitas pasien, pemeriksaan, pengobatan, tindakan dan pelayanan lain kepada pasien pada sarana pelayanan kesehatan ${ }^{4}$. Rekam Medis mempunyai tujuan untuk menunjang tercapainya tertib administrasi dalam rangka upaya peningkatan pelayanan kesehatan di Puskesmas dan Rumah Sakit. Penelitian ini akan menganalisis manajemen pengelolaan sistem rekam medis pada Puskesmas Pal X Kota Jambi.

\section{METODE}

Penelitian ini dilakukan dengan metode penelitian kualitatif, yang bertujuan untuk menggali informasi mendalam tentang manajemen pengelolaan sistem rekam medis di Puskesmas Pal X Kota Jambi. Penelitian dilaksanakan di Puskesmas Pal X Kota Jambi, pada bulan Februari sampai Desember 2018. Subyek pada penelitian ini adalah Petugas Rekam Medis, Kepala Puskesmas Pal X Kota Jambi, Dokter, dan Perawat. Pengambilan sampel dilakukan dengan cara Snowball Sampling dimulai dari petugas rekam medis. Variabel dari penelitian ini 
diantaranya, sumber daya manusia (SDM), sarana dan prasarana, standar operasional prosedur, kerja sama, dan alur rekam medis yang di ukur dengan melakukan wawancara mendalam

\section{HASIL DAN PEMBAHASAN Sumber Daya Manusia}

Petugas rekam medis menjadi aspek utama dalam sirkulasi rekam medis sebuah rumah sakit. Petugas rekam medis mempunyai tugas dan tanggung jawab yang besar dalam menjaga keutuhan sebuah rekam medis. Petugas rekam medis diharapkan benar-benar mengetahui seluk beluk dari rekam medis secara luas dan mendalam. Dari hasil wawancara diketahui sumber daya manusia pada bagian rekam medis masih kurang, karena belum ada petugas dengan latar belakang pendidikan Rekam Medis. Hal ini sesuai dengan data sekunder mengenai tenaga bagian rekam medis yang didapatkan. Pada bagian pendaftaran dan rekam medis tenaga yang tersedia berjumlah lima orang dan tidak ada yang memiliki latar belakang pendidikan rekam medis, melainkan kebidanan dan keperawatan. Berdasarkan jumlah pegawai sudah memadai untuk kebutuhan, sedangkan ditinjau dari kualitas dan keterampilan masih perlu adanya penambahan tenaga kerja dengan berlatar belakang pendidikan rekam medis sehingga mampu bekerja sesuai dengan keahlian yang dimiliki atau melakukan peningkatan pengembangan wawasan dan keterampilan dengan mengikutsertakan pegawai yang ada dalam pendidikan dan pelatihan-pelatihan terkait dengan pengelolaan manajemen rekam medis.

Menurut Keputusan MenKes

No.377/Menkes/SK/III/2007, seorang pegawai rekam medis atau perekam medis harus memiliki kompetensi. Kompetensi tersebut meliputi: 1. Klasifikasi dan Kodifikasi Penyakit dan Masalah- masalah yang Berkaitan dengan Kesehatan dan Tindakan-tindakan Medis Dalam hal ini perekam medis mampu menetapkan kode penyakit dan tindakan dengan tepat sesuai dengan klasifikasi yang diberlakukan di Indonesia (ICD- 10). 2. Aspek Hukum dan Etika Profesi Perekam medis mampu melakukan tugas dalam memberikan pelayanan rekam medis dan informasi kesehatan yang bermutu tinggi dengan memperhatikan perundangan dan etika profesi yang berlaku. 3. Manajemen Rekam Medis dan Informasi Kesehatan Perekam medis mampu mengelola rekam medis dan informasi kesehatan untuk memenuhi kebutuhan layanan medis, administrasi, dan kebutuhan informasi kesehatan sebagai bahan pengambilan keputusan di bidang kesehatan. 4. Menjaga Mutu Rekam Medis Perekam medis mampu merencanakan, melaksanakan, mengevaluasi dan menilai mutu rekam medis. 5. Statistik Kesehatan Perekam medis mampu menggunakan statistik kesehatan untuk menghasilkan informasi dan perkiraan (forcasting). 6. Manajemen Unit Kerja Manajemen Informasi Kesehatan / Rekam Medis Perekam medis mampu mengelola unit kerja yang berhubungan dengan perencanaan, pengorganisasian, penataan dan pengontrolan unit kerja manajemen informasi kesehatan (MIK/ rekam medis di instalasi pelayanan kesehatan. 7. Kemitraan Profesi Perekam medis mampu berkolaborasi inter dan intra profesi yang terkait dalam pelayanan kesehatan ${ }^{5}$.

Melihat uraian diatas dapat disimpulkan bahwa seorang pegawai arsip atau rekam medis selain harus memiliki kualifikasi pendidikan yang ditentukan 
sebagai seorang pegawai rekam medis, seorang pegawai rekam medis harus pintar, cerdas, rapi, teliti, dan tekun dalam melaksanakan tugasnya. Syarat dan kualifkasi rekam medis yang diberlakukan ini berfungsi sebagai dasar peningkatan kualitas Sumber Daya Manusia dalam peningkatan kualitas pelayanan kesehatan rumah sakit. Selain itu, seorang perekam medis harus memiliki semua kompetensi seperti yang disebutkan di atas.

Akan tetapi tenaga kesehatan yang ada sudah terbiasa melakukan pengelolaan menajemen rekam medis, hal ini dapat dilihat dari hasil wawancara tentang pemahaman rekam medis oleh petugas dari ketiga responden yang diwawancarai, seluruh petugas telah memiliki pengetahuan tentang rekam medis yang sudah cukup baik, hal ini dapat dinilai dari hasil wawancara yang menyatakan kalau selama ini kegiatan pengelolaan rekam medis yang berjalan dengan baik dan lancer dan dilakukan selama bertahuntahun. Pemahaman petugas mengenai fungsi dan manfaat rekam medis juga sudah cukup baik diantaranya sebagai kepentingan dokumentasi riwayat penyakit pasien, kebutuhan keluarga pasien, kepentigan hukum, penelitian, serta pelaporan puskesmas terhadap dinas kesehatan. Hal ini didukung oleh penelitian yang telah dilakukan dengan judul rekam medis dan sistem informasi kesehatan disarana pelayanan kesehatan primer (puskesmas) yang menyatakan kegunnaan rekam medis dalam berbagai aspek, diantaranya: (1) Aspek administrasi, Suatu berkas rekam medis mempunyai nilai administrasi , karena isinya menyangkut tindakan berdasarkan wewenang dan tanggung jawab sebagai tenaga mdis dan perawat dalam mencapai tujuan pelayanan kesehatan. (2) Aspek medis, Catatan tersebut dipergunakan sebagai dasar untuk merencanakan pengobatan/perawatan yang harus diberikan kepada pasien. (3) Aspek hukum, Menyangkut masalah adanya jaminan kepastian hukum atas dasar keadilan, dalam rangka usaha menegakkan hukum serta penyediaan bahan tanda bukti untuk menegakkan keadilan. (4) Aspek keuangan, Isi Rekam Medis dapat dijadikan sebagai bahan untuk menetapkan biaya pembayaran pelayanan . Tanpa adanya bukti catatan tindakan /pelayanan , maka pembayaran tidak dapat dipertanggungjawabkan. (5) Aspek penelitian, Berkas Rekam medis mempunyai nilai penelitian, karena isinya menyangkut data/informasi yang dapat digunakan sebagai aspek penelitian. (6) Aspek pendidikan, Berkas Rekam Medis mempunyai nilai pendidikan , karena isinya menyangkut data/informasi tentang kronologis dari pelayanan medik yang diberikan pada pasien. (7) Aspek dokumentasi, Isi Rekam medis menjadi sumber ingatan yang harus didokumentasikan dan dipakai sebagai bahan pertanggungjawaban dan laporan sarana kesehatan ${ }^{6}$.

\section{Sarana dan Prasarana}

Berdasarkan hasil wawancara yang dilakukan, didapatkan bahwa sarana dan prasarana yang tersedia diantaranya rak penyimpanan (lemari), meja, kursi, kartu rekam medis, map penyimpanan, alat tulis untuk pelabelan kartu rekam medis. Dari data yang diperoleh dari wawancara dan hasil observasi yang dilakukan terhadap responden dan ruang penyimpanan rekam medis menganggap bahwa sarana dan prasarana rekam medis di puskesmas Paal $\mathrm{X}$ belum lengkap dan terbatas. Petugas masih mengeluhkan kekurangan map 
sebagai pelindung kartu rekam medis, alatalat penunnjang seperti komputer juga belum ada diruang rekam medis Puskesmas Paal X . ruangan penyimpanan rekam medis juga harus menjadi perhatian. Lokasi ruangan rekam medis harus dapat memberi pelayanan yang cepat kepada seluruh pasien, mudah dicapai dari segala penjuru dan mudah menunjang pelayanan administrasi. Alat penyimpanan yang baik, penerangan yang baik, pengaturan suhu ruangan, pemeliharaan ruangan, perhatian terhadap faktor keselamatan petugas, bagi suatu ruangan penyimpanan rekam medis sangat membatu memelihara dan mendorong kegairahan kerja dan produktivitas pegawai. Penerangan atau lampu yang baik, menghindari kelelahan penglihatan petugas. Perlu diperhatikan pengaturan suhu ruangan, kelembaban, pencegahan debu dan pencegahan bahaya kebakaran.

Rekam medis puskesmas yang merupakan suatu komponen penting dalam pelaksanaan kegiatan manajemen puskesmas harus mampu menyajikan informasi lengkap tentang pelayanan medis dan kesehatan rumah sakit baik dimasa lalu, ataupun di masa sekarang. Sehingga sarana dan prasarana yang menunjang terhadap pelayanan rekam medis sangat diperlukan ${ }^{7}$. Akan tetapi, mencukupinya sarana dan prasarana penunjang pelayanan rekam medis tidak didukung dengan jumlah tenaga yang bekerja di ruang rekam medik dan tidak adanya tenaga yang mempunyai pendidikan khusus tentang rekam medis (D.III rekam medis) menyebabkan tidak dapat dimanfaatkannya sarana dan prasarana dengan maksimal yang akhirnya juga berpengaruh terhadap pelayanan.

\section{SOP}

Berdasarkan hasil wawancara yang dilakukan, dapat dilihat bahwa di Puskesmas Paal X telah memiiki Standar Operasional Kerja (SOP) mengenai rekam medis. Seluruh petugas juga bersama-sama membuat komitmen guna menjalankan seluruh kegiatan yang dilakukan sesuai dengan SOP yang telah diputuskan secara bersama-sama.

Berdasarkan Peraturan Menteri Kesehatan Republik Indonesia Nomor 512/Menkes/PER/IV/2007 Tentang Izin Praktik dan Pelaksanaan Praktik Kedokteran BAB I pasal 1 ayat 10 Standar Prosedur Operasional adalah suatu perangkat instruksi/langkah-langkah yang dibakukan untuk menyelesaikan suatu proses kerja rutin tertentu, dimana ${ }^{8}$ Standar Prosedur Operasional memberikan langkah yang benar dan terbaik berdasarkan konsensus bersama untuk melaksanakan berbagai kegiatan dan fungsi pelayanan yang dibuat oleh sarana pelayanan kesehatan berdasarkan standar profesi. Penerapan prosedur sering menjadi hal yang sulit, meliputi 3 hal $^{9}$ : (1) Adanya prosedur sering memerlukan perdebatan panjang, sehingga prosedur tidak pernah selesai, (2) Penerapannya perlu benarbenar berjalan, tidak hanya jaditulisan saja, dan (3) Pengawasan dan evaluasi harus secara terus-menerus dijalankan agar prosedur benar-benar berjalan semakin baik, bukan hanya sekedar ada.

Prosedur yang istimewa dalam rekam medis termasuk analisa masuk dan keluar, analisa diagram, mengumpulkan data, mengindeks penyakit dan opearasi dan asuransi serta surat-surat. Pada saat prosedur dalam departemen telah direncanakan dan diuji adalah penting 
untuk mencatat tata kerja tersebut dalam tulisan, menggambarkan setiap langkah demi langkah secara rinci. Beberapa pekerja harus dapat mengikuti penjelasan tertulis dan dengan pertanyaan yang minim dalam melaksanakan setiap tata kerja, menunjang hal tersebut tidak perlu pengetahuan teknis yang banyak adalah penting untuk menampilkan pekerjaan ${ }^{10}$.

\section{Kerjasama}

Kerjasama yang dilakukan rekam medis di puskesmas Paal X terdapat pada Loket Pendaftaran,Pelayanan Upaya Kesehatan perorangan, seperti Pelayanan Poli Umum, Pelayanan Poli Gigi, Pelayanan Poli KIA, Pelayanan Poli Anak,Pelayanan Poli Anak, Pelayanan Poli Lansia, Pelayanan Imunisasi,Pelayanan Konsultasi, Pelayanan Laboratorium, dan Pelayanan Farmasi atau Obat. Setiap Pelayanan UKP diatas bekerja sama dengan rekam medis untuk dilakukan pencatatan sampai penyimpanan rekam medis pasien, mulai dari Loket Pendaftaran sebagai tempat pendaftaran Pasien, Lalu mengisi data Pasien hingga di alihkan ke Poli Pelayanan Sesuai dengan Kebutuhan Pasien. Setelah sampai ke Poli Pelayanan Pasien akan diperiksa oleh Dokter untuk selanjutnya di catat diagnosa pasien dan penanganannya, selanjutnya akan diantar ke Pelayanan Farmasi untuk diberikan obat pada pasien jika diperlukan, lalu Semua berkas dan pencatatan untuk rekam medis diperiksa oleh tim Pengolahan Rekam medis, serta tim Penyimpanan untuk di arsipkan. Semua kerjasama yang dilakukan oleh Puskesmas Paal X berdasarkan Observasi peneliti dirasa sudah baik dikarenakan dapat memenuhi kebutuhan rekam medis dari pendaftaran, pencatatan, sampai ke tahap penyimpanan atau pengarsipan.

\section{Alur Rekam Medis}

Dari hasil wawancara yang dilakukan, didapatkan bahwa alur rekam medis yang ada di Puskesmas Pal X dimulai dari Pasien mengambil nomor antrian, lalu mendaftar di loket pendaftaran, selanjutnya pengisian data pribadi pasien dan tanggal berobat serta poli yang akan dituju, setelah itu kartu rekam medis akan diantar oleh petugas ke poli tujuan, setelah dipanggil, pasien akan diperiksa dan dicatat diagnose penyakit pasien dan penanganannya untuk menjadi arsip rekam medis Puskesmas Pal X, namun Informasi alur rekam medis yang didapatkan dari responden diatas tidak menyebutkan Alur rekam medis sampai ke tahap penyerahan rekam medis ke bagian pengolahan untuk pengkodingan diagnosa sesuai dengan buku ICD X dan selanjutnya diserahkan ke bagian pemantauan untuk diperiksa kelengkapan berkas rekam medis pasien untuk selanjutnya dibuatkan nama pasien pada bagian sampul folder rekam medis pasien dan terakhir diserahkan kebagian penyimpanan untuk diarsipkan.

\section{KESIMPULAN DAN SARAN}

Kesimpulan yang didapatkan dalam penelitian ini adalah masih kurangnya sumber daya manusia yang ada di bagian rekam medis Puskesmas Paal X dari segi kuantitas dan keterampilan petugas, masih diperlukan penambahan petugas terutama yang memiliki latar belakang pendidikan rekam medis dan juga diperlukan pelatihan ataupun pendidikan mengenai rekam medis kepada petugas yang ada. Sarana dan prasarana di bagian rekam medis juga masih kurang memadai,, masih diperlukannnya penambahan sarana dan 
prasaran sebagai penunjang pengelolaan rekam medis. SOP yang ada di bagian rekam medis sudah ada dan sudah dijalankan dengan komitmen bersama. Kerjasama tiap-tiap bagian yang berhubungan dengan rekam medis sudah sesuai dengan SOP, begitu pula alur rekam medis.

Adapun saran yang dapat diberikan yaitu menambah jumlah petugas rekam medis dengan latar belakang pendidikan sesuai standar yang telah ditentukan, memberikan pelatihan dan pendidikan yang dibutuhkanan mengenai rekam medis kepada petugas yang ada, menambah sarana dan prasarana penunjang rekam medis yang dibutuhkan sesuai standar yang telah ditentukan.

\section{DAFTAR PUSTAKA:}

1. Trihono. 2005. Manajemen Puskesmas Berbasis Paradigma Sehat. Jakarta: CV Sagung Seto

2. Depkes RI. 2006. Pedoman Penyelenggaraan dan Prosedur Rekam Medis Rumah Sakit di Indonesia.Jakarta: Depkes RI

3. Depkes, RI. 1997. Pedoman Pengelolaan Rekam Medis Rumah Sakit di Indonesia. Jakarta: Departemen Kesehatan RI.

4. Peraturan Menteri Kesehatan RI Nomor 749a/MENKES/PER/XII/1989 tentang rekam medis/Medical Record.

5. Menkes RI. 2007. Keputusan Menteri Kesehatan Republik Indonesia Nomor : 377/Menkes/SK/III/2007 Tentang Standar Profesi Perekam Medis dan Informasi Kesehatan. Jakarta.

6. Gondodiputro, S., 2007, Rekam Medis dan Sistem Informasi Kesehatan di
Pelayanan Kesehatan Primer

(Puskesmas), 1, Bagian Ilmu

Kesehatan Masyarakat Fakultas

Kedokteran Universitas Padjadjaran, Bandung.

7. Henny Maria Ulfa, (2007), Penyimpanan Berkas Rekam Medis

Pasien di Rumah Sakit Anak dan

Bersalin Eria Bunda Pekanbaru, Pekanbaru

8. Peraturan Menteri Kesehatan Republik Indonesia Nomor 46 Tahun 2015 Tentang Akreditasi Puskesmas, Klinik Pratama, Tempat Praktik Mandiri Dokter, dan Tempat Praktik Mandiri Dokter Gigi. www.depkes.go.id.

9. Sabarguna B S. 2005.Sistem Informasi Manajemen Rumah Sakit. Yogyakarta: Konsorium RSI Jateng dan DIY

10. Suwarti, S.. 1996. Modul Kuliah Aplikasi Rekam Medis. Program DIII AKK FKM UI. Depok. 